\title{
Economic evaluation of ezetimibe combined with simvastatin for the treatment of primary hypercholesterolaemia
}

\author{
F. van Nooten • G. M. Davies • J. W. Jukema • \\ A. H. Liem • E. Yap • X. H. Hu
}

Published online: 28 January 2011

(C) Springer Media / Bohn Stafleu van Loghum 2011

\begin{abstract}
Objective This study aims to assess the cost-effectiveness of ezetimibe plus simvastatin (E/S) versus atorvastatin or simvastatin monotherapy as second-line treatment of primary hypercholesterolaemia from the Dutch healthcare perspective. Methods The evaluation used a Markov model and patient data from the Dutch EASEGO study in which patients failing to reach goal low-density lipoprotein cholesterol levels on atorvastatin $10 \mathrm{mg}$ or simvastatin $20 \mathrm{mg}$ had their dose doubled or switched to ezetimibe $10 \mathrm{mg}$ plus generic simvastatin $20 \mathrm{mg}$ (E10/S20). The second scenario, based on Dutch guidelines, switched patients from simvastatin $40 \mathrm{mg}$ to atorvastatin $40 \mathrm{mg}$,
\end{abstract}

The questions can be answered after the article has been published in print. You have to $\log$ in to: www.cvoi.nl.

F. van Nooten $(\bowtie)$

United BioSource Corporation,

26-28 Hammersmith Grove,

London W6 7HA, UK

e-mail: floortje.vannooten@unitedbiosource.com

G. M. Davies

Merck Research Laboratories,

Upper Gwynedd, PA, USA

\section{J. W. Jukema}

Leiden University Medical Center, Department of Cardiology,

Leiden, the Netherlands

\section{A. H. Liem}

Admiraal de Ruyter Ziekenhuis, Department of Cardiology,

Goes, the Netherlands

\section{E. Yap}

Schering-Plough,

Houten, the Netherlands

X. H. Hu

Merck \& Co., Inc,

West Point, PA, USA or ezetimibe $10 \mathrm{mg}$ was added to simvastatin $40 \mathrm{mg}$ (E10/S40). The key effectiveness input measure was change in total cholesterol/high-density lipoprotein ratio obtained from the EASEGO study. In conformity with published studies linking reduced lipid levels to reduced risk of cardiovascular events, the present model assumed that a lipid decrease with ezetimibe may be a signal for reduced risk of cardiovascular events. Model parameters were derived from published literature. Sensitivity analyses were performed for the key parameters.

Results In the EASEGO scenario, incremental costeffectiveness ratio for E10/S20 was $€ 3497 /$ quality-adjusted life-years (QALY) vs atorvastatin $20 \mathrm{mg}$ and $€ 26,417 /$ QALY vs simvastatin $40 \mathrm{mg}$. In the Dutch guidelines scenario, E10/S40 was dominant (more effective and costsaving) vs atorvastatin $40 \mathrm{mg}$. Varying model inputs had limited impact on the cost-effectiveness of E/S.

Conclusions The analysis showed the cost-effectiveness of E/S versus atorvastatin $20 \mathrm{mg}$ or simvastatin $40 \mathrm{mg}$ (EASEGO scenario) at a threshold of $€ 30,000 /$ QALY and vs atorvastatin $40 \mathrm{mg}$ was dominant (Dutch guidelines). Thus, E/S seems a valuable cost-effective second-line treatment option for patients not attaining lipid treatment goals.

Keywords Hypercholesterolaemia · Ezetimibe . Cost-effectiveness

\section{Introduction}

Cardiovascular disease (CVD) and coronary heart disease (CHD) cause considerable morbidity and mortality and are estimated to cost $€ 192$ billion annually in the European Union $[1,2]$. The magnitude of treatment-related cardiovascular benefit is proportional to the degree of reduction in low-density lipoprotein cholesterol (LDL-C) levels [3, 4]. 
Therapeutic benefit is generally assessed by surrogate endpoints as measures of CVD events [5].

Statins interfere with endogenous synthesis of cholesterol, reduce LDL-C levels and improve CVD outcomes [4]. Ezetimibe selectively inhibits intestinal cholesterol uptake [6]. Combined ezetimibe-statin therapy impacts both pathways to provide significant incremental reduction in LDL-C levels, benefits endothelial function, arterial stiffness, biomarkers of inflammation and subclinical atherosclerosis, and avoids the need for multiple statin dose adjustments [6-11]. Patients with CHD failing to reach goal lipid levels on a statin achieved LDL-C levels $<2.5 \mathrm{mmol} / 1$ when switched to ezetimibe $10 \mathrm{mg}$ added to simvastatin $40 \mathrm{mg}(\mathrm{E} 10 / \mathrm{S} 40)$ [12] or ezetimibe $10 \mathrm{mg}$ added to simvastatin $20 \mathrm{mg}$ (E10/S20) [13]. Patients with type 2 diabetes failing to achieve goal LDL-C levels on a statin achieved target LDL-C levels and had decreased carotid artery intimal medial thickness when switched to ezetimibe-simvastatin (E/S) [14]. Compared with placebo, $\mathrm{E} / \mathrm{S}$ reduced ischaemic cardiovascular events by $22 \%$ during a median 52-month follow-up [15].

Several studies have reported on the cost-effectiveness of statin and E/S therapy in country-specific healthcare settings [10, 16-21]. Given the lack of information on cost-effectiveness on E/S-induced lipid modification within the Dutch healthcare system, the present analysis was initiated using clinical data from the Dutch EASEGO study [11] and statistical data from the Dutch Guideline on Cardiovascular Risk Management 2006 and the Dutch Healthcare Performance Report 2008 [22]. The current Dutch guidelines recommend using ezetimibe with statins as second-line treatment. Healthcare spending in the Netherlands was estimated at $€ 49$ billion (2006) and expected to increase at an annual rate of 5\% [22]. Amid growing costs and pressures on healthcare resources, it is increasingly critical for treatments to be cost-effective.

\section{Methods}

\section{Overview}

A decision-analytic model based on a Markov model [16, 17] assessed the cost-effectiveness of E/S within the Dutch societal perspective using EASEGO study clinical data from patients failing to achieve goal LDL-C on simvastatin [11], Dutch guidelines statistical data [23], Dutch mortality data [22] and Framingham risk equations [24, 25]. Indirect costs due to productivity loss were not considered.

\section{Treatment Settings}

The model evaluated two treatment scenarios-the EASEGO study (Fig. 1) [11] and the Dutch guidelines (Fig. 2) [23]. The EASEGO study used E10/S20 fixed-dose combination tablets (Inegy ${ }^{\mathrm{TM}}$ ). However, this economic evaluation used the costing structure of E10-generic simvastatin $20 \mathrm{mg}$ (S20). Patients failing to achieve target LDL-C on S20 or atorvastatin $10 \mathrm{mg}$ (A10) entered the model. The model assumed that all patients were on the same baseline statin dose (whether atorvastatin or simvastatin). In the Dutch guidelines setting, patients not attaining LDL-C targets on generic S40 were switched to A40, or had E10 added to S40. Adding E10 to S40 was assumed to have the same efficacy as adding E10 to S20 or switching from A10 to E10/S20.

\section{Model Structure}

Risk factors and current health status determine the probability of an individual transitioning from one health state to another during a given year (cycle). Health states in the model reflect the phases in CHD progression. Patients without established CHD start in the primary prevention module and might progress to a primary fatal or nonfatal CVD event, die from non-CVD causes or remain alive without CVD. Following a primary nonfatal event, patients receive secondary prevention, and might subsequently experience a recurrent CVD event or die from non-CVD causes. Probability determinations were used to calculate the annual risk of CVD events based on Framingham risk equations [24] and the risk of death from non-CVD causes derived from Dutch mortality data [22] and projected over the lifetime. The Framingham risk equations were used to estimate the probability of an event being fatal CVD, nonfatal MI or nonfatal angina.

The impact of any treatment modification within the model is reflected in a probabilistic change in the patient's lipid profile with consequently altered CVD risk and health
Fig. 1 Schematic overview of the EASEGO study scenario

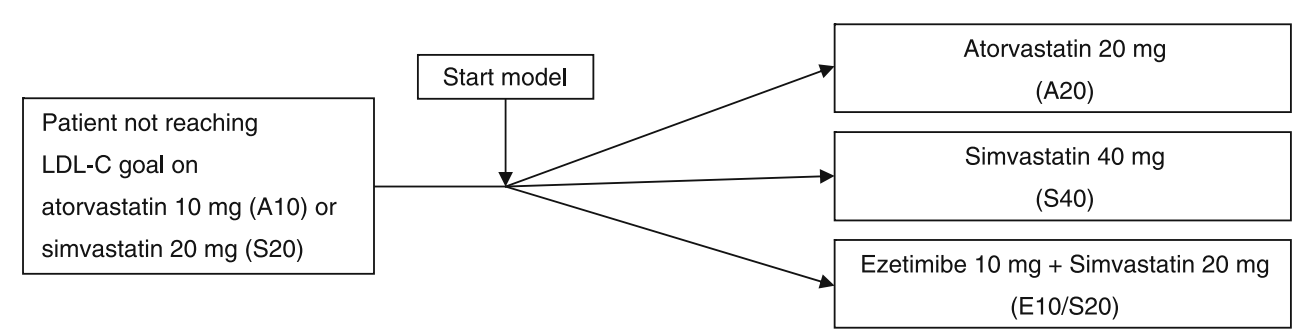


Fig. 2 Schematic overview of the Dutch guidelines scenario

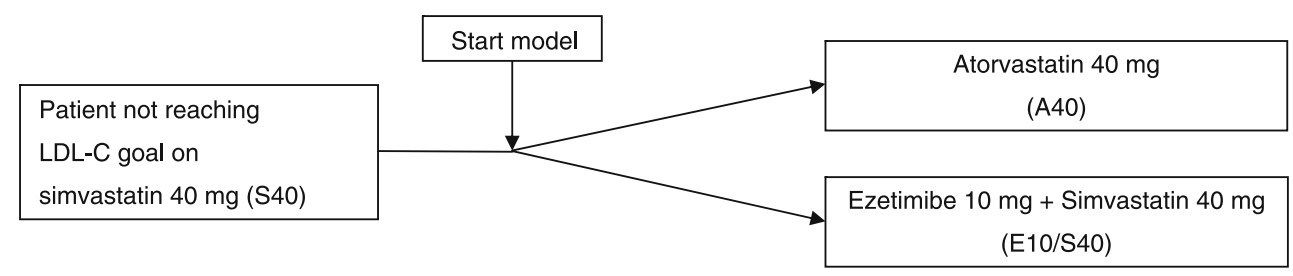

state over time [4, 18]. Accordingly, the present model assumed that ezetimibe-associated lipid level decreases are associated with a CVD risk reduction. Every health state was assigned an expected cost to determine the costeffectiveness of treatment strategies, and was associated with a utility value between 0 and 1 , indicating the quality of life associated with that health state during the 1-year cycle. Changes in the patient's utility score reflect changes in lipid levels and health states. The number of qualityadjusted life-years (QALYs) gained from a treatment strategy was calculated by multiplying the patient's utility score with the relevant time period. Thus, for a patient with an average utility score of 0.77 , every succeeding year would add 0.77 QALYs. The model was run until all patients reached the age of 100 years. The model used Dutch guideline discount rates ( $4 \%$ for costs and $1.5 \%$ for outcomes) [26]. Results from this analysis were calculated with and without discounting and presented as cost/QALY.

\section{Model Inputs: Patient Characteristics}

Baseline patient data (Table 1) for both treatment settings were based on the EASEGO study, which included patients with CHD on a stable ( $\geq 4$ weeks) statin dose (S20 or A10) failing to attain goal LDL-C $(\leq 2.5 \mathrm{mmol} / \mathrm{l})$ [11].

Table 1 Patient characteristics in EASEGO study

\begin{tabular}{ll}
\hline Baseline parameters & EASEGO patients $(n=367)$ \\
\hline Mean age (years) (SD) & $64.6(9.7)$ \\
Female (\%) & $24.3 \%$ \\
Mean LDL-C (mmol/l) (SD) & $3.1(0.5)$ \\
Mean HDL-C (mmol/l) (SD) & $1.3(0.3)$ \\
Mean TGs (mmol/l) (SD) & $1.6(0.6)$ \\
Mean total-C (mmol/l) (SD) & $5.0(0.6)$ \\
History of CHD (\%) & $97.3 \%$ \\
Systolic blood pressure (mmHg) (SD) & $137.6(17.8)$ \\
Diabetes (\%) & $12.3 \%$ \\
Smoker ${ }^{\mathrm{a}}(\%)$ & $19.9 \%$ \\
Use of hypertensive medications (\%) $^{\circ}$ & $42.0 \%$ \\
\hline
\end{tabular}

$L D L$ low-density lipoprotein, $H D L$ high-density lipoprotein, $C$ cholesterol, $T G$ triglycerides, $C H D$ coronary heart disease, $S D$ standard deviation

${ }^{\text {a }}$ Not available: imputed from National Statistics [11]
Model Inputs: Treatment Efficacy

The EASEGO study primary efficacy endpoint was a goal LDL-C level $<2.5 \mathrm{mmol} / \mathrm{l}$ [11]. Patients receiving E/S achieved an additional $29.1 \%$ reduction in LDL-C compared with doubling statin monotherapy dose. Similar changes were obtained in mean total cholesterol (TC), triglycerides (TG), high-density lipoprotein cholesterol (HDL-C), apolipoprotein (apo-B) and TC/HDL ratio. Because the Framingham risk equations are based on $\mathrm{TC} /$ HDL ratios $[24,25]$, the present evaluation used pooled percentage changes in the TC/HDL ratio derived as a ratio of changes in TC and HDL using data from the EASEGO study [11] as key parameter to assess clinical benefit (Table 2). The model assumed that the lipid changes were similar for the A10-to-A20 and S20-to-S40 titrations. Furthermore, the effects of adding E10 to S20 or E10 to S40 in the EASEGO study and of adding E10 to S40, or of adding E10 to S20, or switching from A10 to E10/ S20 in the Dutch guidelines scenario were assumed to be similar.

\section{Other Model Inputs}

Event and utility costs and Dutch medication prices are listed in Table 2. Non-CVD-related mortality rates were taken from Statline 2008 [15]. Age-specific event-related utility values were generated by multiplying the eventrelated utility value by the age-specific Dutch EQ-5D Forms 2009 [33, 34].

\section{Outcomes of Cost-Effectiveness Analyses}

Comparisons of the relative costs and outcomes of interventions are typically expressed as the incremental cost-effectiveness ratio (ICER) in CE analysis and indicate the cost for an extra unit of health gain in terms of a specific measure (QALY; Fig. 3). At issue in the present evaluation is the projected lifetime cost of E10/S20 therapy compared with statin monotherapy.

Sensitivity Analyses: One-Way Sensitivity Analyses

One-way sensitivity analyses assessed the sensitivity of outcomes to changes in key model parameters: use of the ezetimibe-branded simvastatin combination instead of 
Table 2 Main model inputs

\begin{tabular}{|c|c|c|c|}
\hline Input & & PSA distributions & Source \\
\hline \multicolumn{4}{|l|}{$\%$ change in total cholesterol } \\
\hline Double statin dose (mean (SE)) & $-6.6(0.7)$ & Normal & [11] \\
\hline Add ezetimibe to statin therapy (mean (SE)) & $-17.7(0.7)$ & Normal & [11] \\
\hline \multicolumn{4}{|l|}{$\%$ HDL-C change } \\
\hline Double statin dose (mean) & 1.0 & & [11] \\
\hline Add ezetimibe to statin therapy (mean) & -2.6 & & [11] \\
\hline \multicolumn{4}{|l|}{ Costs of events } \\
\hline 1st year & $€ 1101$ & Normal ( $\pm 25 \%$ used for PSA) & {$[27]$} \\
\hline Subsequent year & $€ 1101$ & Normal ( $\pm 25 \%$ used for PSA) & [27] \\
\hline 1st year & $€ 7972$ & & [28] \\
\hline Subsequent year & $€ 1101$ & & [27] \\
\hline Fatal CHD & $€ 1832$ & & {$[28]$} \\
\hline \multicolumn{4}{|l|}{ Utility } \\
\hline Angina (mean (SE)) & $0.77(0.038)$ & Beta & [29] \\
\hline MI (mean (SE)) & $0.76(0.018)$ & Beta & [29] \\
\hline \multicolumn{4}{|l|}{ Costs of monitoring } \\
\hline Specialist & $€ 66.81$ & & {$[26,30,31]$} \\
\hline General practitioner & $€ 20.60$ & & {$[26,30,31]$} \\
\hline Liver function test & $€ 12.85$ & & {$[26,30,31]$} \\
\hline Lipid panel test & $€ 7.05$ & & {$[26,30,31]$} \\
\hline \multicolumn{4}{|l|}{ Dutch medication prices (pharmacy purchase price per tablet) } \\
\hline Lipitor (atorvastatin) coated tablet $10 \mathrm{mg}$ (A10) & $€ 0.75$ & & {$[32]$} \\
\hline Lipitor (atorvastatin) coated tablet $20 \mathrm{mg}$ (A20) & $€ 1.18$ & & {$[32]$} \\
\hline Lipitor (atorvastatin) tablet $40 \mathrm{mg}(\mathrm{A} 40)$ & $€ 1.55$ & & {$[32]$} \\
\hline Simvastatin tablet $20 \mathrm{mg}$, generic (S20) & $€ 0.02$ & & {$[32]$} \\
\hline Simvastatin tablet $40 \mathrm{mg}$, generic (S40) & $€ 0.03$ & & {$[32]$} \\
\hline Ezetrol (ezetimibe) tablet $10 \mathrm{mg}$ (E10) & $€ 1.29$ & & [32] \\
\hline Ezetrol+simvastatin $20 \mathrm{mg}(\mathrm{E} 10 / \mathrm{S} 20)$ & $€ 1.31$ & & $-^{\mathrm{a}}$ \\
\hline Ezetrol+simvastatin $40 \mathrm{mg}(\mathrm{E} 10 / \mathrm{S} 40)$ & $€ 1.32$ & & $-{ }^{b}$ \\
\hline Inegy (ezetimibe/simvastatin) tablet 10/20 mg (E/S 10/20) & $€ 1.63$ & & {$[32]$} \\
\hline Inegy (ezetimibe/simvastatin) tablet 10/40 mg (E/S 10/40) & $€ 1.91$ & & {$[32]$} \\
\hline
\end{tabular}

PSA probabilistic sensitivity analysis, $M I$ myocardial infarction, $C H D$ coronary heart disease

${ }^{\text {a }}$ Summation of the price of E10 with S20

${ }^{\mathrm{b}}$ Summation of the price of E10 with S40

ezetimibe-generic simvastatin, lipid-lowering efficacy, utility due to nonfatal MI or angina, treatment cost of MI and angina and estimated risk of CVD events.

\section{Probabilistic Sensitivity Analyses}

The impact of any treatment modification is reflected in a probabilistic change in lipid levels, which can alter patients' CVD risk and modify their movement among different health states over time. Probabilistic sensitivity analysis (PSA), based on a simulation approach, considers all input parameters as random quantities by assigning a probability distribution. It allows multiple input variables to be changed simultaneously. Each health state is assigned the country-specific expected cost. These values were sampled and lifetime costs and effects calculated. The process was repeated 1000 times to generate an empiric distribution of ICER estimates. The PSA results are presented as a cost-

\footnotetext{
ICER $=\frac{\text { Cost of } A-\text { Cost of B }}{\text { Effectiveness of } A-\text { Effectiveness of B }}$

A = Ezetimibe/simvastatin therapy

$\mathrm{B}=$ Doubling of statin dose or switching to more potent statin
}

Fig. 3 Calculation of incremental cost-effectiveness ratio (ICER) 
Table 3 Results of combination ezetimibe/simvastatin therapy versus statin monotherapy

\begin{tabular}{lllll}
\hline $\begin{array}{l}\text { EASEGO } \\
\text { scenario }\end{array}$ & Cost $(€)$ & Life-years & QALYS & $\begin{array}{l}\text { ICERs (cost/QALY) } \\
\text { E/S vs corresponding } \\
\text { statin }\end{array}$ \\
& & & \\
\hline
\end{tabular}

Not discounted

$\begin{array}{lllll}\text { A20 } & 26,950 & 16.66 & 13.93 & \\ \text { S40 } & 19,956 & 16.66 & 13.93 & \\ \text { E10/S20 } & 28,157 & 16.99 & 14.20 & \\ \text { Discounted } & & & & \\ \text { A20 } & 18,220 & 14.16 & 11.85 & 3,497 \\ \text { S40 } & 13,495 & 14.16 & 11.85 & 26,417 \\ \text { E10/S20 } & 18,941 & 14.41 & 12.06 & \\ \text { Guidelines scenario } & & & \\ \text { Not discounted } & & & \\ \text { A40 } & 29,200 & 16.66 & 13.93 & \\ \text { E10/S40 } & 28,219 & 16.99 & 14.20 & \\ \text { Discounted } & & & & \\ \text { A40 } & 19,741 & 14.16 & 11.85 & \text { Dominant }^{\mathrm{a}} \\ \text { E10/S40 } & 18,983 & 14.41 & 12.06 & \end{array}$

ICER incremental cost-effectiveness ratio, $A$ atorvastatin, $S$ simvastatin, $E$ ezetimibe

${ }^{\mathrm{a}} \mathrm{E} 10 / \mathrm{S} 40$ has more QALY gains and is less costly than A40

effectiveness acceptability curve (CEAC) for the EASEGO scenario to illustrate the percentage of replicates below a given cost-effectiveness threshold, and on a costeffectiveness plane (scatter plot) for the guidelines scenario.

\section{Results}

Most patients (97.3\%) in the EASEGO study had a history of CHD (Table 1). In the EASEGO treatment setting, E10/S20 offered the most life-years (16.99 not discounted; 14.41 discounted) and QALYs gained (14.20 not discounted; 12.06 discounted) compared with A20, A40 or S40 monotherapy

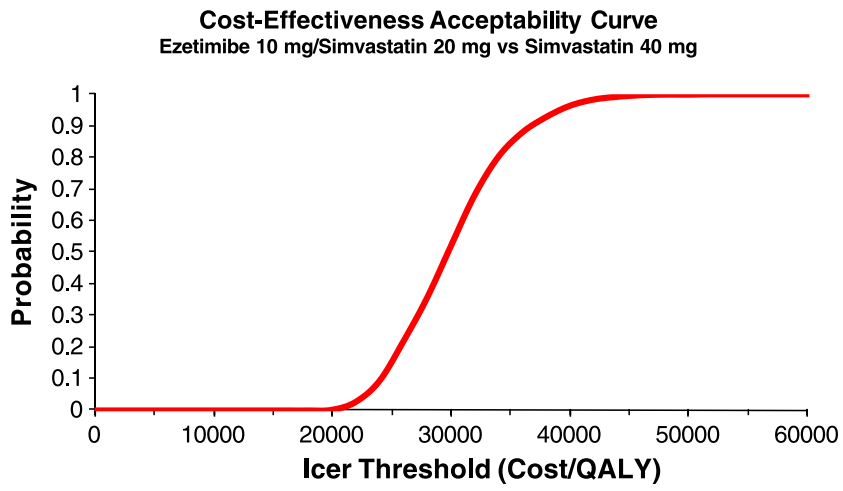

Fig. 4 Cost-effectiveness acceptability curve ezetimibe $10 \mathrm{mg} / \mathrm{sim}$ vastatin $20 \mathrm{mg}$ vs simvastatin $40 \mathrm{mg}$
(Table 3). The cost of E10/S20 was $€ 18,941$ and for A20 $€ 18,220$. The ICER for E10/S20 compared with A20 was $€ 3497 / \mathrm{QALY}$ and versus generic S40 was €26,417/QALY.

In the Dutch guidelines scenario, E10/S40 had a discounted QALY gain of 12.06 and a lower cost $(€ 18,983)$ compared with a discounted QALY gain of 11.85 and cost of $€ 19,741$ on A40. Thus, based on the ICER, E10/S40 dominates making the E10/S40 more effective and less costly with consequent savings from the Dutch perspective (Table 3).

Sensitivity Analyses

Changing the assumptions had no impact on the results except between the use of branded E10/S40 for generic E10/S40. Although branded E10/S40 had higher ICERs, it remained cost-effective at $€ 9967 / \mathrm{QALY}$ versus A20 and $€ 32,887 / \mathrm{QALY}$ versus S40.

The CEAC (EASEGO scenario) shows that at a willingness to pay (WTP) threshold of $€ 20,000$, the acceptability of E10/S20 versus S40 is poor but favourable versus A20 (Fig. 4). At a WTP threshold of $€ 30,000$, the probability of E10/S20 being cost-effective is $50 \%$. At a $€ 40,000$ threshold, E10/S20 is cost-effective versus S40. The PSA (Dutch guidelines scenario) on the CE plane shows that when uncertainty is considered for multiple input parameters, E10/S40 is cost-saving and more effective versus A40 (Fig. 5).

\section{Discussion}

The base-case EASEGO scenario demonstrated the CE of E10/ S20 at the $€ 30,000 / \mathrm{QALY}$ threshold. The estimated ICER was $€ 3497 / \mathrm{QALY}$ versus A20 and €26,417/QALY versus generic S40. The Dutch guidelines scenario showed E10/S40 is costsaving versus atorvastatin and dominant over A40.

An earlier European study found the ICER for E/S was below $€ 18,000$ against statin dose-titration and below $€ 26,000$

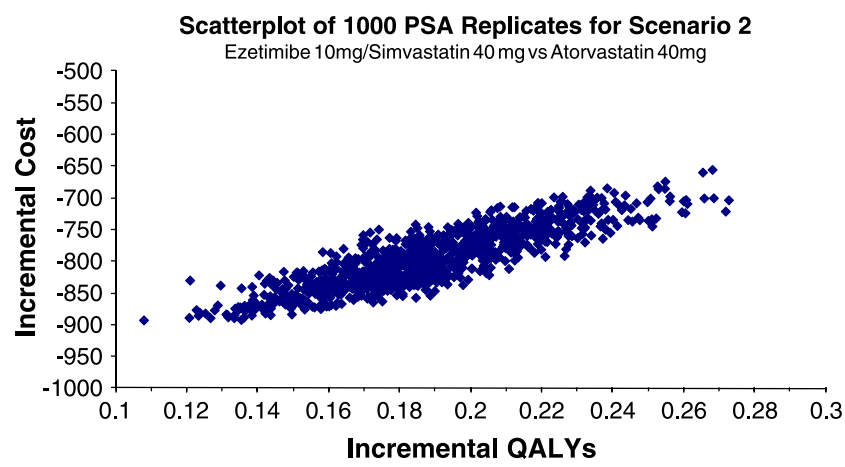

Fig. 5 Scatterplot of 1000 PSA replicates for scenario 2 ezetimibe $10 \mathrm{mg} /$ simvastatin $40 \mathrm{mg}$ vs atorvastatin $40 \mathrm{mg}$ 
versus aggressive 'titrate-to-goal' strategy [16]. A UK study estimated that E/S prevented 43 nonfatal MIs, seven nonfatal strokes and 26 cardiovascular deaths compared with statin titrated by one dose. Moreover, E/S was cost-effective at $£ 30,000 / \mathrm{QALY}$ and the ICERs were below the $£ 20,000$ / QALY compared with branded atorvastatin [20].

The current evaluation assumed that E/S-related LDL-C decreases reduce CVD risk consistent with published evidence [7, 18-20]. The present analysis and other published data demonstrate that $\mathrm{E} / \mathrm{S}$ has a greater probability for achieving goal LDL-C levels compared with statin monotherapy and decreases the risk of CVD events [7, 16]. Longterm follow-up in the currently in-progress IMPROVE-IT trial comparing simvastatin with or without ezetimibe is expected to better address the issue [35]. Until then, the use of the E/S combination relies on extrapolation from studies that have assessed ezetimibe effect on important intermediate steps in the process of atherosclerosis [15].

The present analysis used Framingham Heart Study risk equations [24] that allow evaluation of the risk of fatal and nonfatal CHD events in patients with or without established atherosclerosis. The validity and transportability of the Framingham CHD prediction functions have been tested in multiple ethnic groups [25]. On the other hand, the Dutch guidelines use the SCORE risk functions [23], which include only fatal events and are based on patients without prior CHD and exclude patients with diabetes. The EASEGO study included patients with diabetes and patients with a history of CVD [11]. Based on the recognition that lowering lipid levels significantly reduces the risk of CHD and acute CVD events [7] the present evaluation assumed a similar effect for the E/S combination. Although the primary efficacy endpoint in the EASEGO study [11] was the change in LDL-C levels from baseline, the present analysis used changes in TC/HDL ratios as the key input parameter because TC/HDL ratios were the basis for Framingham risk scores [24, 25].

\section{Conclusion}

From the Dutch perspective, ezetimibe/simvastatin appears to be a cost-effective option for patients not achieving target LDL-C on statin monotherapy. Moreover, E/S appears to be cost-saving and more effective versus atorvastatin. Varying model inputs and model assumptions had no impact on the cost-effectiveness of ezetimibe/simvastatin.

Acknowledgement This work was funded by Merck Sharpe and Dohme/Schering-Plough Pharmaceuticals, the Netherlands. The authors wish to thank Steven Siak of United BioSource Corporation for assistance in the preparation of the manuscript and Carla Vos and Judith Breteler of Merck Sharp \& Dohme Corporation for their valuable comments on the manuscript.

\section{References}

1. Allender S, Scarborough P, Peto V. European Cardiovascular Statistics. Oxford: European Health Network; 2008.

2. Molina JA, Heng BH. Global trends in cardiology and cardiothoracic surgery - an opportunity or a threat? Ann Acad Med Singapore. 2009;38(6):541-5.

3. Law MR, Wald NJ, Rudnicka AR. Quantifying effect of statins on low density lipoprotein cholesterol, ischaemic heart disease, and stroke: systematic review and meta-analysis. BMJ. 2003;326 (7404): 1423 .

4. Dembowski E, Davidson MH. Statin and ezetimibe combination therapy in cardiovascular disease. Curr Opin Endocrinol Diab Obes. 2009;16(2):183-8.

5. Kastelein JJ, de Groot E. Ultrasound imaging techniques for the evaluation of cardiovascular therapies. Eur Heart J. 2008;29 (7):849-58.

6. Goldberg AC, Sapre A, Liu J, et al. Efficacy and safety of ezetimibe coadministered with simvastatin in patients with primary hypercholesterolemia: a randomized, double-blind, placebo-controlled trial. Mayo Clin Proc. 2004;79(5):620-9.

7. Montecucco F, Quercioli A, Mach F. Ezetimibe/simvastatin. Expert Opin Drug Saf. 2009;8(6):715-25.

8. Bays H, Sapre A, Taggart W, et al. Long-term (48-week) safety of ezetimibe $10 \mathrm{mg}$ /day coadministered with simvastatin compared to simvastatin alone in patients with primary hypercholesterolemia. Curr Med Res Opin. 2008;24(10):2953-66.

9. Brudi P, Reckless JP, Henry DP, et al. Efficacy of ezetimibe/ simvastatin $10 / 40 \mathrm{mg}$ compared to doubling the dose of low-, medium- and high-potency statin monotherapy in patients with a recent coronary event. Cardiology. 2009;113(2):89-97.

10. Perkerson KA, Gillespie EL, Coleman CI. Cost-effectiveness of statin monotherapy and combination therapy with ezetimibe. Conn Med. 2005;69(1):19-22.

11. Roeters van Lennep HW, Liem AH, Dunselman PH, et al. The efficacy of statin monotherapy uptitration versus switching to ezetimibe/simvastatin: results of the EASEGO study. Curr Med Res Opin. 2008;24(3):685-94.

12. Reckless JP, Henry P, Pomykaj T, et al. Lipid-altering efficacy of ezetimibe/simvastatin 10/40 mg compared with doubling the statin dose in patients admitted to the hospital for a recent coronary event: the INFORCE study. Int J Clin Pract. 2008;62(4):539-54.

13. Farnier M, Averna M, Missault L, et al. Lipid-altering efficacy of ezetimibe/simvastatin $10 / 20 \mathrm{mg}$ compared with rosuvastatin $10 \mathrm{mg}$ in high-risk hypercholesterolaemic patients inadequately controlled with prior statin monotherapy-the IN-CROSS study. Int J Clin Pract. 2009;63(4):547-59.

14. Fleg JL, Mete M, Howard BV, et al. Effect of statins alone versus statins plus ezetimibe on carotid atherosclerosis in type 2 diabetes: the SANDS (Stop Atherosclerosis in Native Diabetics Study) trial. J Am Coll Cardiol. 2008;52(25):2198-205.

15. Rossebo AB, Pedersen TR, Boman K, et al. Intensive lipid lowering with simvastatin and ezetimibe in aortic stenosis. N Engl J Med. 2008;359(13):1343-56.

16. Cook JR, Yin D, Alemao E, et al. Cost-effectiveness of ezetimibe coadministration in statin-treated patients not at cholesterol goal: application to Germany, Spain and Norway. Pharmacoeconomics. 2004;22 Suppl 3:49-61.

17. Cook JR, Yin D, Alemao E, et al. Development and validation of a model to project the long-term benefit and cost of alternative lipid-lowering strategies in patients with hypercholesterolaemia. Pharmacoeconomics. 2004;22 Suppl 3:37-48.

18. Kohli M, Attard C, Lam A, et al. Cost effectiveness of adding ezetimibe to atorvastatin therapy in patients not at cholesterol treatment goal in Canada. Pharmacoeconomics. 2006;24(8):815-30. 
19. National Institute for Health and Clinical Excellence. Ezetimibe for the Treatment of Primary (heterozygous-familial and non-familial) hypercholesterolaemia. NICE Technology Appraisal Guidance 132. [http://www.nice.org.uk/nicemedia/live/11886/38213/38213.doc] Accessed on 18 Jun 2010

20. Ara R, Pandor A, Tumur I, et al. Estimating the health benefits and costs associated with ezetimibe coadministered with statin therapy compared with higher dose statin monotherapy in patients with established cardiovascular disease: results of a Markov model for UK costs using data registries. Clin Ther. 2008;30 (8):1508-23.

21. Soini EJ, Davies G, Martikainen JA, et al. Population-based healtheconomic evaluation of the secondary prevention of coronary heart disease in Finland. Curr Med Res Opin. 2010;26(1):25-36.

22. Westert GP, van den Berg MJ, Koolman X, et al. Dutch Health Care Performance Report. Bilthoven, the Netherlands: National Institute for Public Health and the Environment. [http://www.rivm.nl/vtv/ object binary/o6118 Dutch\%20Healthcare\%20Performance\% 20Report\%202008.pdf] Accessed 11 Jun 2010

23. Dutch Ministry of Foreign Affairs: Welcome to the Netherlands: Health Care. 2009.

24. D'Agostino RB, Russell MW, Huse DM, et al. Primary and subsequent coronary risk appraisal: new results from the Framingham study. Am Heart J. 2000;139(2 Pt 1):272-81.

25. D'Agostino Sr RB, Grundy S, Sullivan LM, et al. Validation of the Framingham coronary heart disease prediction scores: results of a multiple ethnic groups investigation. JAMA. 2001;286(2):180-7.
26. Oostenbrink J. Handleiding voor kostenonderzoek. Methoden en standaard kostprijzen voor economische evaluaties in de gezondheidszorg. CVZ 2005.

27. Greving JP, Buskens E, Koffijberg H, et al. Cost-effectiveness of aspirin treatment in the primary prevention of cardiovascular disease events in subgroups based on age, gender, and varying cardiovascular risk. Circulation. 2008;117(22):2875-83.

28. van Hout BA, Simoons ML. Cost-effectiveness of HMG coenzyme reductase inhibitors; whom to treat? Eur Heart J. 2001;22(9):751-61.

29. Goodacre S, Nicholl J, Dixon S, et al. Randomised controlled trial and economic evaluation of a chest pain observation unit compared with routine care. BMJ. 2004;328(7434):254.

30. College van Zorgverzekeraars: Handboek voor kostenonderzoek 2004 van het College van Zorgverzekeraars. 2009.

31. Nederlands Zorgautoriteit: Tarieflijst zorginstellingen 2009 from the Nederlands Zorgautoriteit. 2009.

32. Z-index, taxe February 2009.

33. Busschbach J, Rabin R, De Charro F, Proceedings of the 24th Scientific Plenary Meeting of the EuroQol Group. Kijkduin. In EuroQoL: The Hague, the Netherlands; 2007.

34. Lamers LM, Stalmeier PF, McDonnell J, et al. Measuring the quality of life in economic evaluations: the Dutch EQ-5D tariff. Ned Tijdschr Geneeskd. 2005;149(28):1574-8.

35. Califf RM, Lokhnygina Y, Cannon CP, et al. An update on the IMProved reduction of outcomes: Vytorin Efficacy International Trial (IMPROVE-IT) design. Am Heart J. 2010;159(5):705-9. 